\title{
O INSTANTE E O MOVIMENTO: a influência da fotografia de Muybridge e Marey
}

\section{Marcos Buccini}

No século XIX, a maneira como artistas e cientistas enxergavam o movimento foi abalada pelo surgimento da cronofotografia, realizada pelo francês Etienne Jules Marey e, posteriormente, o trabalho de Eadweard Muybridge. Nestas fotografias podiam-se enxergar as frações temporais do movimento e visualizar imagens que o olho humano não conseguia captar.

Tais experimentos foram responsáveis pela modificação da visualidade que se tinha sobre o movimento dos seres vivos, a própria capacidade de enxergarmos a nossa realidade, e como a representamos e interpretamos. Causou um grande impacto nas artes, deixando um legado técnico e artístico para formas de expressão já consagradas, como as artes plásticas e para outros que iriam surgir, como o cinema.

Neste texto, discute-se o impacto, em termos expressivos e técnicos, que os trabalhos de Muybridge e Marey tiveram nas artes plásticas e em outros espaços da cultura visual, como nos quadrinhos, na animação e no cinema. A partir das observações apontadas, foi desenvolvido um gráfico que procura visualizar espacialmente a relação destes meios entre si, tendo como base questões importantes trazidas pela cronofotografia, como a singularidade ou multiplicidade da imagem; como ela é criada e a relação com a representação da realidade.

\section{O movimento, o instante e a fotografia: a representação do movimento}

A representação do mundo real variou bastante ao longo da história das artes. Questões como perspectiva, volume e proporções foram representados de maneira mais ou menos realista, dependendo do período histórico, das tecnologias disponíveis, de fatores culturais, ideológicos, religiosos, etc. Um dos aspectos da realidade que é mais desafiador para o ser humano na representação da natureza é o movimento.

Desde a pré-história o ser humano busca representar o registro de seus movimentos. Têm-se apontamentos da tentativa de simular ações através das imagens estáticas, como pode ser observado em pinturas rupestres de animais com oito patas encontradas em cavernas da França (Lascaux) e Espanha (Altamira). Exemplos históricos podem 
ser encontrados, ainda, na antiguidade, em colunas egípcias e vasos gregos (KRASNER, 2008).

Para André Bazin (1991), o ser humano buscava através da arte a perfeição, que só poderia ser conseguida pelo alto nível de fidelidade em relação à natureza retratada. Observada na pintura como uma obsessão humana por uma representação total da natureza, que culminaria com a invenção da fotografia e, consequentemente, do cinema. Desse modo, o autor entende a origem do cinema como a continuidade de um processo que já ocorria nas artes plásticas. Para Bazin, foi a fotografia que libertou a pintura de tal obsessão, por se tratar de um meio sem dúvida mais fiel, capaz de representar a realidade, em certos graus, sem a interferência manual do artista.

\section{O movimento e a fotografia}

Desde seu início a fotografia se impôs o desafio de captar e registrar o movimento. Como o tempo de exposição das primeiras fotos era muito grande, qualquer objeto que se movimentara virava um rastro de luz ou uma silhueta esfumaçada. Só em 1858, a fotografia se tornou instantânea.

Com a fotografia instantânea buscava-se interromper o tempo, aniquilando o seu fluxo, e armazenando sobre o papel fotográfico o instante. Palavra que deve muito de seu significado atual à fotografia: "A fotografia deu visibilidade à unidade instante - como o olho jamais poderia - e o instante, por sua vez, outorgou à fotografia legitimidade e relevância, seja como imagem da ciência, da arte ou da memória” (SANZ, 2012, p. 1).

Segundo Henri BERGSON (1999), o instante inexiste. Ele estaria fora da duração temporal e seria sempre uma abstração resultante da espacialização do tempo. O instante viabilizaria pensar "o instável por meio do estável, o movente por meio do imóvel”. Os instantes seriam, portanto, a suspensão do tempo e sua duração. "O tempo nunca estaria no instante ou, melhor, através do instante jamais poderíamos ver - nem entender - o tempo ou a duração" (SANZ, 2012, p. 1).

Para Susan SONTAG (2004), o instante fotográfico, enquanto apreensão visual de um momento possui uma vibração temporal latente que está impregnado pela percepção do passado e intuição do futuro, uma fração de espaço temporal que possui uma conexão direta com o movimento completo.

Foi nas imagens instantâneas de caráter mais científico, a partir da métrica racional do tempo, que a fotografia ganhou sua importância de índice temporal. Para a ciência fisiológica, a fotografia instantânea foi uma grande ferramenta de estudo do mecanismo de deambulação de animais e seres humanos. Os principais autores que usaram o instante fotográfico para estudar e conhecer o movimento foram Muybridge e Marey.

O trabalho deles mostrou que o tempo pode ser fraturado, ao longo de uma série de imagens incompletas, onde cada fotografia isolada significa uma fração de um movimento complexo e a decomposição do tempo e do espaço. Porém, esta análise do 
instante se dá no interior de uma série e não a partir de uma imagem isolada, o singular e o múltiplo se completam e competem entre si. Ao expor outros instantes e outros fragmentos do mesmo movimento, o trabalho destes autores extrapola o sentido da fotografia instantânea, seja ela a suspensão do tempo ou da vibração temporal, dando um caráter complexo de conjunto, no qual as partes interagem para compor o todo. Neste sentido, os experimentos de Marey e Muybridge não se prendem ao instante fotográfico, e sim a continuidade deste instante, a relação de um instante com o anterior e com sua sequência. Segundo Sanz (2012, p. 1), “todos os instantes se equivaleriam nessa analítica espacializada do tempo moderno: nenhum deles teria o direito de ser uma imagem representativa, nenhum deles se faria como acontecimento".

\section{Étienne- Jules Marey}

Fisiólogo francês e um dos responsáveis pelo uso da cronofotografia para o estudo do movimento dos corpos de pessoas e animais. Para ele, 'o corpo é o teatro do movimento'. Os estudos de Marey serviram à racionalidade instrumental do desenvolvimento industrial, uma época em que a mecanização e a divisão de trabalho nas linhas de produção exigiam eficiência e economia de tempo. Por isso, o estudo da representação gráfica dos movimentos do corpo humano foi tão valorizado, a fim de diminuir a fadiga e ajudar na execução de tarefas. Permitindo que cada ação fosse desmembrada nas suas menores partes constituintes, podendo, assim, serem repetidas, da mesma forma, por qualquer trabalhador (BUKATMAN, 2006).

Marey começou seus estudos tentando recriar os movimentos das asas de pássaros e insetos, assim como a locomoção de cavalos e homens. Para isso, utilizava o Phenakistoscope, ou disco mágico, criado em 1841. Este instrumento foi originalmente projetado para entreter crianças. Nele, desenhos realizados em sequência, eram girados em um cartão de formato redondo e, à medida que o disco girava, podia-se ver o desenho movimentando-se através de pequenos orifícios.

As imagens mostradas pelo Phenakistoscope geralmente tinham movimentos grotescos e irreais. Marey, porém, acreditava que "se os desenhos fossem feitos com cuidado e atenção e representassem fielmente as sucessíveis atitudes do corpo, podia-se ter um entendimento preciso do comportamento fisiológico de homens e animais". Ele então usava tal ferramenta para, através da observação do movimento, desenhar suas fases. Desta forma, ele podia estudar a fragmentação e as etapas de uma determinada ação. Porém, uma vez que a observação era realizada a olho nu, o desenhista não tinha controle sobre cada instante, o que ainda resultava em movimentos imprecisos (BRAUN, 1992. p. 30).

Com o advento da fotografia instantânea, foi possível a captura de momentos 'congelados' no tempo. Marey então visualizou uma oportunidade de substituir os desenhos imprecisos por uma sequência de instantâneos. Surge, desta forma, a cronofotografia, um 
tipo de fotografia que 'se estende' através do tempo. Não mais através de imagens borradas e indefinidas, como o movimento era representado nos primórdios da fotografia, mas a partir de uma sequência de imagens nítidas que mostrava de maneira impressionante o caminho que os corpos percorriam no espaço e no tempo.

Em 1882, Marey começa a usar sua chronophotographic gun, um instrumento semelhante a uma espingarda, que obtinha 12 imagens por segundo e as gravava em uma mesma superfície. Assim, Marey foi a primeira pessoa a gravar uma sequência de imagens usando uma única câmera. No início, a cronofotografia utilizava uma chapa que obtinha apenas silhuetas. Assim, Marey aplicava manchas ou linhas brancas nos modelos vestidos de preto, obtendo, deste modo, uma sequência de pontos e linhas ao invés de volumes (figura 1). Com a utilização de uma fita de papel móvel e, depois, da película de celulose - lançadas em 1888 e 1891, respectivamente, Marey foi capaz de obter imagens com volumes e detalhes, o que o permitiu avançar seus estudos para outros temas, como aves e peixes (figura 2).

"A cronofotografia foi uma tentativa de combinar o poder da fotografia de espelhar objetos no espaço com o poder gráfico de produzir uma expressão visível para a passagem do tempo" (BRAUN, 1992, p. 18). Ela revelava as posições intermediárias entre as diversas etapas de uma ação e os intervalos uniformemente espaçados em uma sequência extraída de movimento contínuo (BUKATMAN, 2006).

Marey usava suas fotografias com um fim bastante objetivo: estudar o movimento de humanos e animais com o intuito científico de aplicar tais conhecimentos nas indústrias e no ramo da fisiologia. Porém, seus experimentos, que permitiram superar os limites da visão retiniana, situavam-se em um campo limítrofe entre a ciência e a arte, chamando a atenção também de artistas e fotógrafos. Seus resultados colocam em xeque o caráter realista da fotografia. "Tratavam-se de imagens que não copiavam a realidade, mas que a transpunham em curvas, ritmos e vibrações” (FABRIS, 2011. p. 84). Estas imagens mostravam os sujeitos de maneira completamente imprevisível, revelando detalhes de uma realidade além do alcance da visão humana.

Além do fato inusitado das imagens de Marey, havia a maneira como estas imagens representavam o movimento, dissolvendo a estrutura do corpo em ritmos abstratos e fluxos de energia. Formas que evoluem no tempo e dentro do espaço da fotografia. As fotos de Marey demonstravam que "a objetividade e transparência, qualidades consideradas intrínsecas à imagem fotográfica, não são dadas, mas produzidas numa incessante superação crítica dos usos e das convenções atribuídos a ela” (FABRIS, 2011. p. 84).

\section{Eadweard Muybridge}

Os registros gráficos eletromecânicos de Marey causaram uma grande repercussão em vários setores da sociedade. Atravessaram o Atlântico e influenciaram a carreira de Eadweard Muybridge, fotógrafo inglês, radicado nos Estados Unidos. 
Antes de se dedicar à fotografia instantânea do movimento, Muybridge era famoso pelas suas fotos panorâmicas de paisagens e fotos stereoscópicas. Em 1872, ele inventa e patenteia um sistema de câmeras com disparadores elétricos ou mecânicos de alta velocidade, que o permitia fazer uma rápida sucessão de exposições múltiplas que duravam frações de segundos cada. Desta forma, começa a experimentar fotos instantâneas do movimento de cavalos. Este tema se deve pela importância que os estudos deste animal, a hipologia, tinha nas atividades econômicas e comerciais da época, fim do século XIX.

Entre 1877 e 1878, financiado por Leland Stanford, ex-governador da Califórnia, Muybridge realiza um conjunto de fotografias sequenciadas das fases da locomoção do cavalo (figura 3). Para tanto, utilizou doze câmeras simultâneas com um obturador que permitia a apreensão da imagem em menos de dois centésimos de segundo. Fios conectados a baterias elétricas pontuavam o trajeto a ser percorrido pelo cavalo: ao rompê-los, o animal acionava as objetivas sucessivamente, tendo como resultado uma série de negativos. Estas imagens iniciais são basicamente silhuetas, porém, são suficientes para provar que, durante o trote, o pequeno galope e o galope, as quatro patas do animal se erguem do solo de uma só vez, o que ia de encontro com a convenção pictórica da época (FABRIS, 2011).

O resultado alcançado por Muybridge era uma sequência de fotos individuais, cada uma trazia em si um determinado instante do fluxo do movimento. Estas imagens eram apresentadas juntas, em exposições e livros; organizadas lado a lado, em uma matriz. A sequência obedecia ao sentido da leitura ocidental de um texto. Assim, as fotos funcionavam como uma historieta linear.

Outra maneira de exibir tais fotos foi através da projeção. Muybridge foi o primeiro a exibir assim imagens obtidas através de fotografias. Baseando-se em inventos como a Lanterna Mágica, o Zoetrope e o Phenakistoscope, em 1879, desenvolveu um projetor primitivo chamado Zoopraxiscope. No início, este instrumento utilizava um disco de vidro com imagens em silhuetas pintadas sobre sua superfície. Em 1982, começou a usar desenhos a traços impressos no vidro fotograficamente e coloridos à mão.

Segundo Bukatman (2006), Braun (1992) e Gunning (2003), Muybridge criou o zoopraxinoscope com o intuito de mostrar suas fotografias em movimento e parecem reconhecer que o objetivo das pesquisas do fotógrafo sempre foi revelar o movimento de animais e pessoas através da fotografia. Porém, ele não estava interessado no instante congelado, ou no arranjo destes instantes em uma matriz apenas. O objeto de estudo de Muybridge não era a totalidade do movimento em si, mas a narrativa que resulta das sequências de imagens instantâneas.

Assim como os experimentos de Marey, as fotografias de Muybridge expuseram a imagem do corpo humano em movimento de modo nunca visto antes, desafiando a noção de verossimilhança com a natureza que se tinha nas imagens da época. Nas imagens de Muybridge pode-se presenciar um relato da visualidade positivista do corpo na era moderna: homens e animais navegavam em um espaço demarcado, enquadrado em grades geométricas e regulares. Estas fotografias capturaram uma nova noção de espaço e 
tempo que surgiu através da transformação tecnológica e do crescimento do pensamento racional (BUKATMAN, 2006; GUNNING, 2003).

\section{Os resultados da cronofotografia}

Os experimentos de Marey e de Muybridge agregam a continuidade à fotografia instantânea, projetando um sentido de seguimento temporal. Para Crary (2000), ao decompor o movimento em uma sequência de instantes, tais autores trazem não só uma quantificação racional do tempo e do movimento ao sentido da mecanização do corpo, mas também uma perspectiva qualitativa do olhar sobre o fluxo e deslocamento de objetos e corpos no tempo e no espaço, através desta nova 'temporalidade mutável', o que sugere uma fuga deste mesmo racionalismo, oferecendo possibilidades plurais imprevisíveis que fogem de qualquer imperativo disciplinar.

Bukatman (2006) discorda desta afirmação de Crary, em relação à Marey, pois, para ele, a cronofotografia claramente não é mutável. Na verdade ela é regida por uma rigidez de intervalos regulares, nitidamente mapeada por vetores de movimento, trazendo a impossibilidade de um momento único, visto que se estendem por todo o campo da imagem.

\section{O cientificismo de Marey e o formalismo de Muybridge}

Tanto Muybridge quanto Marey estavam trabalhando em um mesmo problema: usar a fotografia para capturar, analisar e exibir os estágios que constituem o continuum de um movimento. É notório que eles se conheciam, tinham ciência do trabalho um do outro e até se influenciavam mutuamente.

Porém, existem diferenças significativas entre os dois. A mais obvia é a maneira como as imagens eram capturadas e exibidas. Enquanto Muybridge conseguia uma ilusão cinemática, utilizando diferentes aparelhos que retinham fases distintas de um movimento e as exibia em uma matriz; Marey, utilizando apenas uma câmera, reunia, em uma mesma fotografia, uma série de imagens sucessivas que representam as diferentes posições que um ser vivo ocupa no espaço durante um movimento de locomoção.

Mesmo procurando resolver um problema semelhante, os dois tinham objetivos e chegaram a resultados distintos. Muybridge estava mais interessado na sequência de imagens fixas, dispostas em uma matriz, compostas de maneira textual e narrativa. Já Marey, buscava a totalidade do movimento (BUKATMAN, 2006).

Marey era um cientista, suas fotos, visualmente, estão mais para gráficos científicos que descrevem o fluxo dos corpos no espaço. Já as imagens de Muybridge são mais formalistas. Elas são cuidadosamente iluminadas, enquadradas, compostas - de acordo com as convenções estéticas - e 'contam uma história' no espaço. 
Em relação ao tempo, o uso de Muybridge de múltiplas câmeras espacialmente organizadas, bem como a disposição das fotografias em uma matriz, proporcionam imagens agradavelmente compostas. Uma cena na qual o tempo é dividido, e parcelas constantes do espaço tornaram-se sinônimo de parcelas constantes de tempo. Nas placas individuais de Marey, por outro lado, enfatiza-se um continuum temporal, com a cronofotografia capturando instantes ao longo do eixo 'tempo' (BUKATMAN, 2006; BRAUN, 1992).

Outra questão é a representação natural da realidade. Em Muybridge, fotos individuais e sucessivas de um corpo em movimento se fundem quando exibidas no Zoopraxiscope, criado uma ilusão de vida a partir de imagens estáticas. Mesmo impressas e diagramadas lado a lado, quando os olhos percorrem as fotos de Muybridge, o espectador consegue perceber uma sensação do movimento real do qual as fotos se originaram. Já Marey, sendo um cientista, foi impulsionado por um desejo oposto, entender a estrutura do movimento e não criar uma ilusão perfeita do mundo visível. Suas fotografias exibem um fluxo de imagens sobrepostas que revelam o continuum do corpo na relação tempo e espaço, tudo mostrado em uma mesma imagem.

Neste sentido, Gunning (2003) argumenta que realmente as cronofotografias de Marey possuem qualidades amórficas e fantasmagóricas, que claramente as separa dos contratos da percepção natural. Porém, mesmo utilizando os códigos estéticos de um pictorialismo clássico, as fotos de Muybridge possuem uma qualidade de estranhamento para os padrões visuais da época - as pessoas nunca tinham visto essas imagens antes. Assim, as experimentações de Muybridge combinam a solidez da familiaridade das convenções pictóricas com a radicalmente nova experiência do tempo percebido através das lentes instantâneas da câmera.

\section{Relação com as artes plásticas}

A cena pictórica é marcada pela composição de personagens, objetos e cenários em um determinado enquadramento. Além da relação espacial dos elementos, a imagem do quadro responde pelos gestos, posturas e arranjos dos sujeitos. Pode-se dizer que é a criação, por um artista/pintor, de um momento cênico que representaria uma fração de tempo em uma narrativa e que conceberia a continuidade lógica dos acontecimentos num espaço-tempo (KRAUSS, 2001; NATHER \& BUENO, 2006, p. 217).

Este momento artístico, mesmo em pinturas mais realistas e documentais, possui uma carga subjetiva muito forte. Visto que, mesmo retratando um momento específico de maneira hiper-realista, uma pintura pode, dependendo da técnica empregada, levar bastante tempo para ficar pronta e o pintor nunca conseguiria capturar um instante exato da maneira que ele aconteceu. Assim, faz-se necessário que o pintor, de certa forma, adapte e adeque aquela cena visando um melhor entendimento, uma maior expressão de seus personagens e um resultado estético satisfatório. 
Com o advento da fotografia, especialmente a fotografia instantânea - que não é dirigida e que capta imagens imperceptíveis ao olho humano - o momento artístico se diferencia da cena pictórica, deixando de ser encenado e registrando um instante exato. O fotógrafo da foto instantânea perde o controle das poses, dos gestos e da distribuição espacial dos elementos cênicos. Ele simplesmente escolhe e capta o instante tal qual ele aconteceu.

Uma das consequências da foto instantânea foi a captura de sujeitos em poses consideradas estranhas, incomuns. Isto causou certo descontentamento entre artistas, visto que tais poses podiam ser consideradas esteticamente feias ou rompiam com as convenções dos gestos clássicos que os personagens deveriam ter em uma representação visual.

As fotos de Muybridge e Marey vieram para acirrar esta discussão e tiveram uma enorme influência nas artes plásticas. Uma vez que, além de retratar instantâneos, eles mostravam movimentos em sequências temporais. Assim, foram responsáveis por quebrar diversos cânones das artes plásticas. Um dos mais comentados foi o que diz respeito às posições de um cavalo durante o galopar. Especialmente Marey, que defendia uma visão documental da arte e fez críticas vorazes a representações do movimento de cavalos em diversos quadros "cujas soluções são consideradas errôneas e convencionais por falta de recursos científicos” (FABRIS, 2011, p. 80).

No prefácio do livro de Muybridge, Stillman (apud SCHARF, 1974) afirma que: "A arte é a intérprete da natureza, não se mantém fiel à sua missão quanto persiste obstinadamente na perpetuação da falsidade. (...) artistas que pintam um cavalo em plena corrida da maneira convencional ou num mítico galope não poderão mais afirmar estar representando a natureza tal como parece".

Alguns artistas incorporaram estas novas descobertas, como Jean-Louis-Ernest Meissonier. Ele recebeu Muybridge em seu atelier; começou a estudar atentamente o movimento dos cavalos através de moldes articulados; instalou um trilho no qual pode se deslocar paralelamente ao animal para observá-lo. Tentou, assim, combinar a visão natural com as evidências da ciência, o que pode ser visto no quadro intitulado 1807 (figura 4). Já outros, como Rodin, discordavam do 'aspecto bizarro' que a fotografia instantânea conferia à captação do movimento que seria apenas o congelamento das figuras no espaço, em contraponto do 'desdobramento progressivo do gesto', próprio da arte. Em entrevista ele afirma:

"O artista é quem diz a verdade, a fotografia é que mente, pois na realidade o tempo não para. E se o artista consegue produzir a impressão de um gesto que se executa em vários instantes, o trabalho dele é certamente muito menos convencional do que a imagem científica onde o tempo é suspenso de forma abrupta” (RODIN, 1984, p. 32).

Para Rodin, a representação dos pintores muitas vezes pode ser considerada falsa, do ponto de vista científico, porém a representação pode ser considerada verdadeira se levarmos em conta a percepção do espectador. Para ele, somente esta verdade importa para os artistas, "porque é ela o que vemos e o que nos impressiona" (RODIN, 1984, p. 33). Assim, a arte deturpa e reinterpreta a verdade científica em detrimento do entendi- 
mento e da expressão.

Um exemplo é o caso de 'Corrida de Cavalos em Epson' de Théodore Géricault (figura 5), no qual existe, na mesma figura de um cavalo, fases diferentes de uma mesma ação. Quando isso acontece, segundo Rodin, o artista não "procede desta forma por raciocínio ou artifício. Eles expressam o que sentem. As almas e as mãos dos artistas parecem ser conduzidas na direção do gesto, cujo desdobramento instintivamente eles traduzem" (Ibid, p. 33). Para François Dagognet (apud FABRIS, 2011, p. 80), sim, uma solução errônea se observada pelos critérios científicos, mas que visava "um efeito sugestivo e sintético que lhe permitiu traduzir a energia do animal de maneira muito mais eficaz que o neoclassicismo".

Mas, mesmo os artistas que iam contra os instantâneos de Muybridge também observavam as novas evidências da imagem técnica fotográfica, sendo muitas vezes, direta ou indiretamente, influenciados por ela. Segundo Scharf (1974), não é improvável que algumas fotografias de Muybridge tenham influenciado Rodin ao representar fragmentos do corpo humano em suas esculturas.

Já o historiador da arte Varnedoe (1980 apud FABRIS, 2011) aponta que apesar de artistas como Degas terem se utilizado, ocasionalmente, de imagens "cientificamente isoladas e sistematicamente sequenciadas" (p. 99), as imagens de Muybridge e Marey são puramente resultado de uma metodologia e não do meio usado. Sendo assim, não teriam influenciado a arte no fim do século XIX.

Fabris (2011) argumenta que reduzir as experiências de Marey e Muybridge a uma simples questão de método seria uma leitura capciosa por parte de Varnedoe "em seu afã de criar uma visão absolutamente original da arte de fins do século XIX” (p. 87). Para a autora, seria dificílimo que artistas como Degas, tendo contato direto com os trabalhos fotográficos de sua época, "não poderia ter potencializado um uso anticonvencional de recursos derivados do Renascimento".

Scharf (1974) sugere duas abordagens por parte dos artistas plásticos: aqueles que se baseavam na práxis naturalista preferiam a figuração e o realismo das imagens de Muybridge; já os que davam preferência a realidades mais abstratas seguiam a visualidade sintética de Marey. Degas se identifica com o primeiro grupo, ao procurar dar às suas figuras um ar de congelamento instantâneo; enquanto que no segundo grupo, inscreve-se a presença de algumas obras de Duchamp, especialmente as duas versões do quadro $\mathrm{Nu}$ descendo a escada e também na obra de Giacomo Balla, especialmente após 1912, em quadros como Dynamism of a Dog on a Leash e The Hand of the Violinist.

Os artistas futuristas exaltavam algumas ideias que constituíam o imaginário da modernidade baseando-se nas novas tecnologias da época, como as locomotivas, os carros, as máquinas da indústria, o cinema, etc. Enaltecia-se o sentido de velocidade, dinamismo, violência e agressividade. Desta forma, suas obras procuravam representar essa nova sociedade através de imagens enérgicas, ágeis e agitadas.

No texto "A pintura futurista. Manifesto técnico" podem-se encontrar diversas questões confluentes entre as cronofotografias e as ideias de uma nova visualidade do 
futurismo, como a inspiração no dinamismo visual, com base em instrumentos mecânicos que ampliam o poder do olho humano. Sobre esta questão, o manifesto propõe duas formas de representação: "a concepção do gesto como sensação dinâmica; e a captação de um corpo em movimento em termos de multiplicação, deformação, vibração" (FABRIS, 2011, p. 63).

Porém, nem todos os artistas futuristas concordavam com a representação científica e fragmentada das cronofotografias. Em 1911, Anton Giulio Bragaglia publica um texto chamado Fotodinamismo, no qual ele nega os meios que decompõem o movimento, como o cinema e as experimentações da cronofotografia. Para ele, tanto um quanto o outro não conseguem "traduzir o fluxo contínuo e homogêneo no tempo", pois eles imobilizam o movimento em "seus estados possíveis". Para Bragaglia, o trabalho de Marey e Muybridge não representa nem reconstrói a sensação do movimento. Isto se dá, pois, a trajetória e o fluxo que desmaterializam os objetos e pessoas e apreendem seu ritmo são negligenciados em detrimento da unidade fria e mecânica do instante (FABRIS, 2011).

\section{Influência nos quadrinhos}

O entendimento do tempo para a cultura do fim do século XIX oscilava entre a compreensão do tempo como sendo algo desligado, mutável e múltiplo; e como sendo rígido, determinista e linear. Esta dualidade se deu muito devido a avanços tecnológicos em meios como a fotografia e, mais adiante, o cinema. No campo da fotografia, a foto instantânea e a maneira como Marey e Muybridge a utilizaram em suas experimentações representam um momento crucial na separação do tempo e da sua percepção (BUKATMAN, 2006).

Neste sentido, o cinema (especialmente o de animação) e as histórias em quadrinhos são os dois meios que mais claramente derivam e foram influenciados pelos experimentos de captura do movimento, incorporando aspectos das cronofotografias no estilo e nas narrativas destes meios.

Quadrinhos e cinema estão ligados à exploração do tempo e do ritmo. Porém, os quadrinhos exibem um interesse mais evidente na temporalidade, assim, possuem uma ligação mais direta com o trabalho de Muybridge do que o cinema. Nos quadrinhos os quadros são colocados no espaço em uma sequência legível que obedece a um continuum do tempo, mantendo a matriz sincrônica do espaço-temporal, ou do 'mapa temporal'. O ritmo é ditado pelo olho do espectador; há uma percepção de múltiplos quadros que estão semanticamente ligados entre si, formando um conjunto; e, além disso, existe a percepção do instante, que retrata momentos precisos da narrativa unindo o momentâneo e o causal.

Diferentemente, o cinema funciona a partir da projeção em sequência de quadros fixos, mas que não são percebidos com imagens isoladas, e sim como imagem em movimento. O ritmo é ditado pelo frame rate, ou pelos quadros por segundos que são exibidos 
e não existe a percepção do instante e sim do tempo fluido e contínuo.

Os quadrinhos sofreram grande influência em seu conteúdo e forma depois que Muybridge exibiu suas matrizes fotográficas que fragmentavam o movimento no tempo e espaço. A começar pela maneira que foram dispostos os seus quadros de ação. Assim como nos experimentos de Muybridge, os quadrinhos criam um fluxo de ação temporal entre as suas unidades gráficas, geralmente em uma sequência linear; e cada quadro, mesmo sendo uma imagem completa, relaciona-se com o todo. Este diálogo, entre o imobilismo de uma imagem individual e o movimento espaço-temporal da sequência é chamado por McCloud (1993) de 'mapa temporal'.

Grandes desenhistas de quadrinhos procuravam imitar os pontos de vista fixos e métrica progressiva do movimento da cronofotografia, mas sempre caricaturando o rigor científico das fotos. Um dos bons exemplos desta influência é o trabalho de Winsor McCay, que desenhava seus personagens em poses muito dinâmicas que ofereciam uma continuidade visual, um fluxo cinético e um naturalismo extraordinário à cena retratada - uma perfeita interação entre a analogia cinética e estática. Outro recurso muito comum utilizado por McCay, e claramente inspirado na obra de Muybridge, são as sequências de ações que seus personagens realizam em quadros sucessivos.

Mais um exemplo é a tira francesa Chat Noir, desenvolvida por Adolphe Willette e Théophile-Alexandre Steinlen. Nela um gato preto, desenhado de forma bastante realista, se envolve em diversas confusões com peixinhos dourados e novelos de lã. $\mathrm{O}$ que impressiona nestas tiras é a simplicidade cênica, na qual praticamente não há cenários, só um fundo branco, e também a precisa expressão corporal do gato e um domínio impressionante do tempo, tanto na passagem de uma pose para a outra quanto na apreensão quase fotográfica do instante. "Aqui o movimento é mapeado em um passo mais vagaroso e preciso, com uma científica exatidão pré-cinematográfica” (BUKATMAN, 2006, p. 92).

\section{O Pré-cinema}

A maioria dos textos que tratam do pré-cinema trazem as experiências de Marey e, especialmente, as de Muybridge como fundamentais para o surgimento da sétima arte. Tais experimentos, ao fracionar o movimento real em quadros, precederam a base material fundamental para o surgimento da sétima arte, a película fílmica. Outras experiências já haviam sido realizadas em instrumentos como o Zoetrope e o Zoopraxiscope, porém estes utilizavam desenhos, que em termos indiciais, estão mais longe da realidade do que a fotografia.

Em termos de técnica e suporte, as fotografias sequenciadas de Muybridge e, principalmente, o seu projetor primitivo Zoopraxiscope foram criações que antecederam e contribuíram para o aparecimento do cinema. Fazendo parte da evolução material do meio. Os discos rígidos de vidro deram lugar à película cinematográfica, o que permitiu a captura de mais quadros e com uma qualidade maior de imagem. 
Outro ponto em comum é que ambos capturam o movimento natural e o divide em quadros fixos, sequenciados e independentes. Neste sentido, a câmera fílmica está mais para a chronophotographic gun, de Marey, do que para as câmeras independentes e emparelhadas de Muybridge.

Porém, em termos conceituais e de linguagem, as fotos sequenciadas na verdade são o oposto do que o cinema propõe, uma vez que este usa imagens estáticas em sequência para criar a sensação do movimento real e as fotos de Muybridge e Marey criam uma sequência de imagens estáticas a partir de movimentos reais.

Mesmo assim existe uma aproximação perceptual das imagens de Muybridge em relação ao cinema: a sensação da cinemática. Esta impressão pode ser comprovada quando se percorre com os olhos as matrizes fotográficas de Muybridge. Uma prévia, uma antecipação do que seria o cinema em alguns anos.

\section{Contribuição para o cinema de animação}

Os quadrinhos e a animação, podem ser vistos como consequências naturais do experimentos da fotografia no século XIX. Enquanto que no cinema captura-se o movimento, na animação ele é criado, modificado e controlado. A animação existe em termos conceituais desde os instrumentos primitivos como Zoetrope e o Praxinoscope. Mas, foi com a película cinematográfica que a animação encontrou um suporte que a permitisse crescer artisticamente e narrativamente.

Enquanto que para o cinema live-action (aquele em que câmera captura a imagem em movimento que está a sua frente) as imagens de Muybridge e Marey foram apenas experiências precedentes, para o cinema de animação, elas serviram de base para a formação de técnicas e linguagem.

A navegação calculada de um corpo através do espaço é cuidadosamente mapeada em desenhos animados, o que, de forma clara, iniciou-se na cronofotografia de Marey (BUKATMAN, 2006). Também se pode ver influência de Marey em exercícios utilizados para o ensino das técnicas de animação, quando o animador aprende a desenhar as figuras em suas trajetórias de movimento.

Os experimentos de Marey e de Muybridge, ao fragmentarem o movimento, foram importantíssimos para a criação da técnica da animação e do estudo do movimento de personagens. Uma vez que na animação o movimento não é propriamente capturado, ele é criado, as imagens destes autores serviram como base de pesquisa para o entendimento de como personagens se movem no espaço e tempo. Ajudaram a formar, assim, técnicas e expressões gráficas de uma nova arte, o desenho animado, inclusive influenciando a criação das 12 regras de ouro da animação, inventadas e aperfeiçoadas por Walt Disney.

Vale salientar que diversas técnicas foram usadas para a criação de um vocabulário gráfico no cinema de animação. Inclusive, algumas, baseadas nas artes plásticas, que deturpavam e iam 'contra' a representação racional do movimento, como o borrado 
usado por alguns artistas para representar um deslocamento rápido. Situação que lembra as colocações de Rodin ao defender a manifestação do artista acima da veracidade científica das imagens e os movimentos expressivamente borrados do Fotodinamismo dos Bragaglia.

\section{Considerações}

Neste trabalho, procurou-se discutir um pouco como os experimentos fotográficos de Muybridge e Marey contribuíram, ou influenciaram outras artes. Algumas que, inclusive, ainda nem existiam, como o cinema e o cinema de animação. Acredita-se que tais experimentos realmente tiveram um grande impacto na época, século XIX, e que realmente deixaram diversos legados, tanto tecnicamente, quanto artisticamente. Visto que foram responsáveis pela modificação da visualidade que se tinha sobre o movimento dos seres vivos, a própria capacidade de enxergarmos a nossa realidade, e como a representamos e interpretamos artisticamente e expressivamente.

Durante o estudo da importância das fotos de Muybridge e Marey e sua relação com outras formas artísticas, notou-se que alguns assuntos serviam de base comparativa e eram considerados fundamentais para a discussão destes trabalhos. Entre os assuntos que foram considerados mais relevantes estão: a representação do instante; a relação da imagem unitária e a imagem múltipla; a origem da imagem; e a questão da representação da realidade.

Baseando-se nestes conceitos e como resultado das observações feitas ao longo do texto, foi criado um gráfico que serve para visualizar a relação dos meios artísticos a partir da qualidade da imagem que o forma. Este gráfico possui dois continuums: um horizontal que estabelece a relação da formação da imagem, se ela é criada manualmente ou capturada mecanicamente; e um vertical, que se relaciona com a multiplicidade da imagem, ou seja, se o meio utiliza-se de imagens únicas ou de uma sequência. Para completar, uma linha diagonal foi traçada para indicar no espaço a questão da representação da realidade.

Deve-se destacar que este gráfico serve para representar de maneira geral a relação entre os meios artísticos e técnicos abordados neste artigo. Não se considera que o gráfico seja um trabalho finalizado, mas sim, que possa ser modificado e melhorado. A intenção do autor é que este gráfico possa servir de ferramenta para novas reflexões acerca da cronofotografia e sua influência nas artes plásticas, fotografia, animação, cinema e etc.

\section{Referências}

BAZIN, André. O Cinema: Ensaios. São Paulo: Editora Brasiliense, 1991.

BERGSON, Henri. Matéria e memória: ensaio sobre a relação do corpo com o espírito. 
São Paulo: Martins Fontes, 1999.

BRAUN, Marta. Picturing Time: The Work of Etienne-Jules Marey (1830-1904). Chicago: University of Chicago Press, 1992.

BUKATMAN, Scott. Comics and the Critique of Chronophotography, or 'He Never Knew When It Was Coming! Animation. Sage. Disponível em: http://anm.sagepub.com/ content/1/1/83. 2006. Acesso em 26 de junho de 2010.

CRARY, Jonathan. Suspensions of perception: Attention, Spectacle, and Modern Culture. Boston, MA: MIT Press, 2000.

FABRIS, Annateresa. O Desafio do olhar: fotografia e artes visuais no período das vanguardas históricas, volume 1. São Paulo: WMF Martins Fontes, 2011.

GUNNING, Tom. 'Never Seen This Picture Before: Muybridge and Multiplicity', in Philip Prodger (Ed.) Time Stands Still: Muybridge and the Instantaneous Photography Movement, pp. 222-72. Nova York: Oxford University Press, 2003.

KRASNER, Jon. Motion Graphic Design: Applied History and Aesthetics. Burlington: Focal Press, 2008.

KRAUSS, Rosalind E. Caminhos da escultura moderna. São Paulo: Martins Fontes, 2001. MCCLOUD, Scott. Understanding Comics: The Invisible Art. Northampton, MA: Tundra Publishing, 1993.

NATHER, Francisco Carlos; BUENO, José Lino Oliveira. Tempo subjetivo e percepção de movimento em obras de arte. Estudos de Psicologia, vol. 11, n. 3, p. 265-274, 2006.

PHÉLINE, Christian. L’image accusatrice. Laplume: AACP, 1985.

RODIN, Auguste. Art: conversations with Paul Gsell. Los Angeles: University of California Press, 1984.

SANZ, Claudia. Quando o tempo fugiu do instantâneo. Studium. n.32. Unicamp. Acesso em: 21/11/2012. Disponível em: http://www.studium.iar.unicamp.br/32/4.html

SCHARF, Aaron. Art and photography. Harmondsworth: Penguin, 1974.

SONTAG, Susan. Ensaios sobre fotografia. São Paulo: Companhia das Letras, 2004. 